\title{
The newly graduated Canadian urologist: Over-trained and underemployed?
}

\author{
Blayne Welk, MD, FRCSC, MSc, ${ }^{*}$ Ron Kodama, MD, FRCSC; ${ }^{+}$Andrew MacNeily, MD, FRCSC ${ }^{\S}$
}

*Assistant Professor, University of Western Ontario, London, ON; †Professor, University of Toronto, Toronto, ON; §Professor, University of British Columbia, Vancouver, BC

Cite as: Can Urol Assoc J 2013;7(1):E10-E15. hitp://dx.doi.org/10.5489/cuaj.12095

\section{Abstract}

Introduction: There are two prevailing perceptions among urology residents (1) fellowship training is becoming a requirement after residency, and (2) there are few job opportunities after graduation. In this study, we examine postgraduate training patterns and employment choices of urology residents.

Methods: All Canadian urology program directors provided a summary of fellowship training and employment of Canadian residents graduating between 1998 and 2009. Logistic regression models were used to detect linear trends.

Results: In total, 258 Canadian urology residents graduated over the study period, with a median of 22 (interquartile range 21-22) graduating per year. Of these, $72 \%$ completed a fellowship. Of these fellowships, $62 \%$ included protected research time. The most common subspecialty area was minimally invasive surgery (MIS)/ endourology (39\% of fellowships). There was a significant increase in fellowship training over time $(p<0.0001)$; this was mostly due to an increase in MIS/endourology fellowships. The number of urologists obtaining graduate degrees after medical school has increased significantly over the study period. Almost all graduates are employed. Of the employed graduates in total, 34\% are academic urologists. Among all graduates, 50\% are practicing within $100 \mathrm{~km}$ of their residency site, $16 \%$ are practicing in the United States and $22 \%$ are in rural practice. There has been no significant change over time in the proportion of residents practicing within $100 \mathrm{~km}$ of their training program, practicing rurally, leaving their province of training, practicing in the United States, or choosing academic practice.

Conclusions: Fellowship training, especially in MIS/endourology, has become significantly more common. Graduate degrees are more frequently being obtained. We did not find evidence that there has been a significant change in a urology resident's ultimate ability to obtain employment upon graduation.

\section{Introduction}

In an attempt to control health care spending, Canadian medical school enrolment was cut by $20 \%$ during the 1990 s.
The resulting reduction in new graduates contributed to a critical shortage of physicians in Canada. ${ }^{1,2}$ This policy was reversed in 1999, and over the next decade the number of newly admitted medical students increased by almost 1000 students to a total of 2830 in $2010 .^{3}$ This has led to an increase in residency spots across most specialties, and this proportional increase has kept the match rate of medical students to their first choice discipline relatively constant $(85 \%-88 \%) .{ }^{4}$ In urology, the number of training spots has doubled, from 15 spots in 2002 to 31 spots in 2011. There are multiple stakeholders who decide on the number of specialists to train, and this makes it difficult to ensure that enrolment numbers are balanced with employment opportunities.

Newly graduated surgical specialists, such as orthopedic ${ }^{5}$ and cardiovascular ${ }^{6}$ surgeons have struggled to find employment in Canada. The specialty committee for cardiovascular surgery reduced Canadian training positions, and now may face a shortage of cardiac surgeons in the future. ${ }^{7}$ There is an increasing demand for orthopedic care in our aging society, but paradoxically many new graduates are unable to find employment. ${ }^{8}$ The Royal College of Physicians and Surgeons of Canada (RCPSC) is currently examining similar issues across all surgical disciplines. ${ }^{9}$

Urology is faced with similar questions about its' training programs. Training spots have increased, and this has led to a perception among urology residents that there are not enough employment opportunities available for new graduates. $^{10}$ The purpose of this study was to examine the postresidency training, education and employment choices of Canadian urologists in the 12 years between 1998 and 2009.

\section{Methods}

In Canada there are 12 urology residency programs. Urology program directors were our primary data source because of their knowledge of the relevant variables in our study; program directors are often used as references for fellow- 
ship applications, they are involved in job recruitment, and are usually a required reference for hospital privileges at the beginning of a urologist's career. In addition, urology programs in Canada are generally small, with a median of 2 (range: 0-5) residents a year, making the required recall of individual residents manageable.

We contacted all the program directors from Canadian universities with urology residents to gather information about their graduating residents between 1998 and 2009 . We excluded international medical graduates. The program directors submitted a standard electronic report that summarized fellowship training and employment of Canadian residents graduating. We then reviewed the reports to ensure standard data coding.

Our final dataset included the following training variables: year of graduation, residency program completed, length of fellowship after residency, fellowship subspecialty area, research training during fellowship (a binary variable defined as at least 1 day per week of protected time for research, or a research year in a multiyear fellowship), and graduate degrees obtained during residency or fellowship (graduate degrees prior to residency were not considered).

The following employment variables were collected: whether the former resident is an academic urologist (defined as a rank of at least assistant professor and working in a hospital with regular urology resident rotations), whether they are currently a clinician scientist (defined as protected time for basic science research) and their current city and country of practice. The 2006 Canadian census was used to add population sizes for the city of practice. The distance between the training program and the city of practice was determined using an online distance calculator. To assess for trends over time, we grouped 2 consecutive graduating years together, which resulted in the 12-year period divided into sextiles. Institutional ethics approval was obtained for this study.

\section{Statistical methods}

Data is presented as proportions and medians. Where appropriate, the interquartile range (IQR) is reported. Logistic regression models were used to assess for the significance of linear trends within binary variables over time; results are reported as odds ratios (OR) with 95\% confidence intervals $(\mathrm{Cl})$. Significant results from these models were confirmed using the ungrouped year variable to ensure significant trends were not the result of grouping our data into sextiles. A $p<0.05$ was considered significant. SAS 9.2 (SAS Institute, Cary, NC) was used for statistical analysis.

\section{Results}

We had a $100 \%$ response rate from the 12 program directors. They identified a total of 258 Canadian residents who had graduated over the 12 -year study period. Less than $3 \%$ of the values for any variable were classified as missing. Each training program contributed a median of 4 (IQR: 2-5) residents per sextile (with each sextile representing 2 consecutive years) (Table 1). A median of 22 (IQR: 21-22) Canadian urology residents graduated each year; this number has not changed significantly over time $(p=0.6701)$.

\section{Postgraduate training}

Within the total cohort of graduating urology residents, $72 \%$ $(185 / 258)$ undertook fellowship training. The length of fellowship was 0.5 to 1 year $(38 \%, 71 / 185), 1.5$ to 2 years $(52 \%, 97 / 185)$ and 2.5 to 3 years $(9 \%, 17 / 185)$. Protected time for research was included in $62 \%(114 / 185)$ of these fellowships; this percent increased to $86 \%$ (95/111) when considering only the fellowships greater than or equal to 2 years. A total of 193 fellowships were completed by the 185 residents (8 residents completed fellowships across 2 different disciplines). The most popular area of fellowship training was minimally invasive surgery (MIS) and endourology $(39 \%, 75 / 193$, Figure 1, part A).

A total of 28 residents (11\%) obtained advanced degrees during residency (10/258), or during fellowship (20/185). The most popular degree programs were a Masters in Clinical Epidemiology $(29 \%, 8 / 28)$, Masters of Science $(25 \%, 7 / 28)$ and Masters of Education (21\%, 6/28).

\begin{tabular}{|c|c|c|c|c|c|c|c|c|c|c|c|c|c|c|}
\hline Year & Sextile & UBC & $U$ of $A$ & $\mathbf{U}$ of Man & Western & McMaster* & $\mathbf{U}$ of $\mathbf{T}$ & Queens & $\mathbf{U}$ of $\mathrm{O}$ & McGill & U de $\mathbf{M}$ & Laval & Dalhousie & Total \\
\hline 1998-99 & 1 & 3 & 5 & 2 & 2 & 0 & 8 & 2 & 2 & 6 & 4 & 2 & 4 & 40 \\
\hline $2000-01$ & 2 & 4 & 2 & 2 & 3 & 0 & 5 & 2 & 3 & 6 & 5 & 5 & 4 & 41 \\
\hline 2002-03 & 3 & 6 & 5 & 2 & 4 & 0 & 8 & 2 & 4 & 7 & 3 & 2 & 5 & 48 \\
\hline 2004-05 & 4 & 5 & 2 & 2 & 4 & 0 & 7 & 3 & 4 & 6 & 3 & 4 & 4 & 44 \\
\hline 2006-07 & 5 & 6 & 3 & 1 & 2 & 1 & 6 & 2 & 5 & 3 & 5 & 4 & 5 & 43 \\
\hline 2008-09 & 6 & 6 & 3 & 2 & 4 & 2 & 7 & 1 & 4 & 4 & 4 & 1 & 4 & 42 \\
\hline Total & & 30 & 20 & 11 & 19 & 3 & 41 & 12 & 22 & 32 & 24 & 18 & 26 & \\
\hline
\end{tabular}

UBC: University of British Columbia, Vancouver, BC; U of A: University of Alberta, Edmonton, Alberta; U of Man: University of Manitoba, Winnipeg, Manitoba; Western: Western University, London, Ontario; U of T: University of Toronto, Toronto, Ontario; Queens: Queens University, Kingston, Ontario; U of O: University of Ottawa, Ottawa, Ontario; McGill: McGill University,

Montreal, Quebec; U de M: Université de Montréal, Montreal, Quebec; Laval: Université Laval, Quebec City, Quebec; Dalhousie: Dalhousie University, Halifax, Nova Scotia.

*McMaster University started a urology residency program during the study time period, and graduated their first Canadian resident in 2007. 


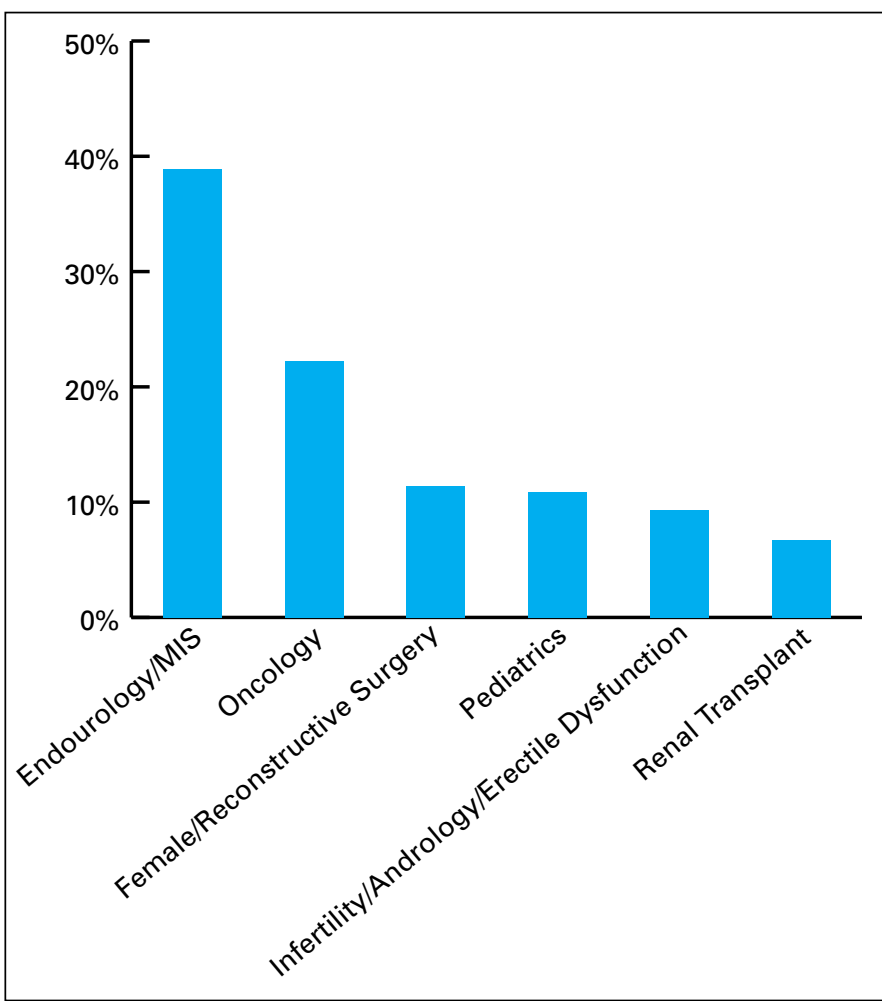

Fig. 1. Proportion of residents (among the 185 who completed fellowship training) selecting specific subspecialty training areas (overall [panel A], and over time [panel B]).

There was a significant increase in the proportion of residents pursuing fellowship training over time $(p<0.0001)$ (Fig. 2, Table 2). Among those who completed a fellowship, the length in years of fellowship training did not significantly change over time $(p=0.6600)$. There was a significant increase over time in advanced degrees earned during residency and fellowship over time $(p=0.0314)$. The proportion of residents selecting a specific subspecialty only changed significantly within the endourology/MIS group over time (Figure 1, part B, OR 1.247 per sextile, 95\% Cl 1.038-1.490, $p=0.0181)$. Endourology/MIS was the only subspecialty significantly associated with community practice $(p=0.0041)$.

\section{Practice patterns}

Almost all urology residents who graduated between 1998 and 2009 were employed at the time of this study (>98\%). Of these, 34\% (85/254) work as academic urologists, and $12 \%(30 / 254)$ as clinician scientists (Table 3). Of the 85 working in the academic setting, 65\% (55/85) work at the university where they completed their residency. We also tallied the proportion that went on the academic careers among subspecialty disciplines (Table 3 ). Half of the residents $(127 / 254)$ practice within $100 \mathrm{~km}$ of where they completed their training. Among residents working in Canada,

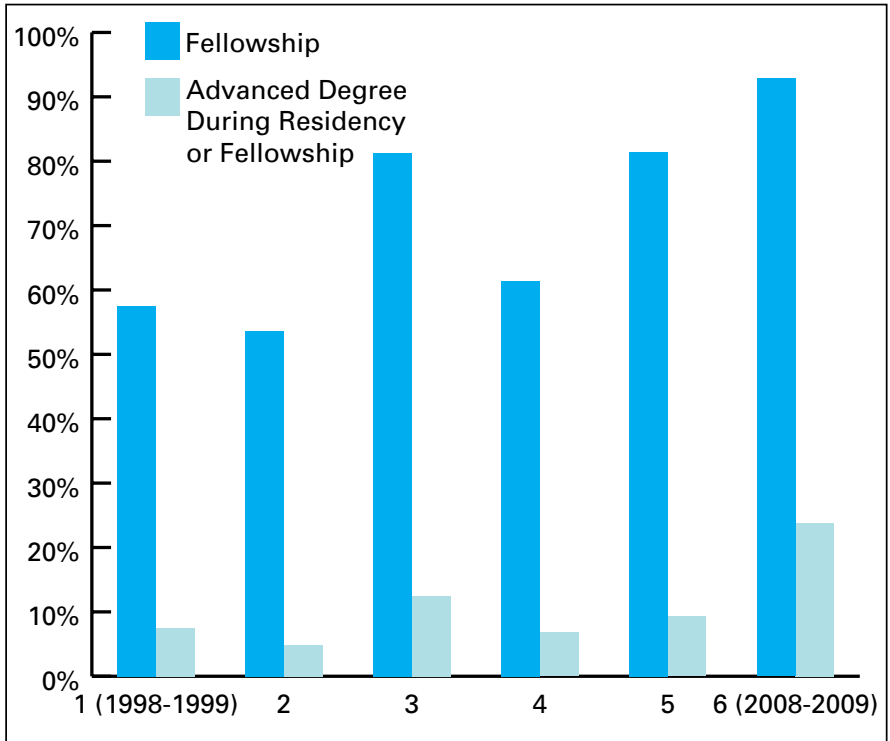

Fig. 2. Trend in the proportion of residents between 1998-2009 who obtained fellowship training and graduate degrees.

$24 \%(51 / 214)$ left the province they trained in to practice in another province in Canada. In total, 22\% (56/254) of residents practice in a city with a population of less than 100,000 . In total, $16 \%$ (40/254) of residents currently practice in the United States. Of the urologists practicing in the United States, $41 \%$ are at academic institutions. Academic urologists are more likely to have: completed a fellowship (especially one with research training), obtained a graduate degree during residency or fellowship, a practice near their training program, and a practice in a large city (Table 4).

There has been no significant change over time in the proportion of residents practicing within $100 \mathrm{~km}$ of their training program, practicing in a rural location, leaving their province of training, practicing in the United States, choosing academic practice, or becoming a clinician scientist (Table 2).

\section{Discussion}

Fellowship training is an essential part of acquiring specialized surgical skills, and is necessary for academic practice. Among uro-oncologists, this additional training may translate into better oncologic outcomes. ${ }^{11}$ The field of urology continues to rapidly expand; new technology is leading to innovative surgical procedures, and there is a continual increase in relevant clinical knowledge. Our results demonstrate that fellowship training is increasingly common among Canadian urologists; 93\% of residents graduated between 2008 and 2009 chose to complete a fellowship. This increase in fellowship training, which was traditionally associated with academic practice, does not seem to be associated with an increased need for academic urologists 
Table 2. Trends over time in fellowship and employment choices*

\begin{tabular}{lcc}
\hline & $\begin{array}{c}\text { Odds ratio per } \\
\text { sextile (95\% Cl) }\end{array}$ & p value \\
\hline Fellowship training & 1.423 & $<0.0001^{*}$ \\
Fellowship with research training & $(1.194-1.694)$ & \\
& 1.049 & 0.6021 \\
Graduate degree during & $(0.877-1.255)$ & \\
residency/fellowship & 1.313 & $0.0314^{*}$ \\
Practicing within 100 km of & $(1.025-1.682)$ & \\
training program & 0.926 & 0.3011 \\
Left province of training program & $(0.800-1.072)$ & \\
Practicing in city with $<100,000$ & 1.117 & 0.1641 \\
population & $(0.956-1.305)$ & \\
Practicing in the United States & 0.981 & 0.8356 \\
& $(0.823-1.171)$ & \\
Academic practice & 1.107 & 0.3281 \\
& $(0.903-1.358)$ & \\
Clinician scientist & 1.013 & 0.8701 \\
\hline The odds ratio represents the odds over time, based on increasing 2 year time periods; an \\
odds ratio of $>1$ means the outcome was more common over the study period. \\
Cl: confidence interval. & $(0.866-1.186)$ & \\
\hline
\end{tabular}

as there has not been a concurrent increase in urologists obtaining an academic appointment.

The increase in fellowship training has primarily occurred within the subspecialty of MIS/endourology. The use of MIS techniques has rapidly become a standard among all surgical specialties because of patient demand and economic pressures to shorten hospital stays. A survey of Canadian urologists in 2003 found that MIS surgery and percutaneous renal access were perceived as the most relevant subspecialty areas for clinical practice. ${ }^{12}$ Acquisition of these skills are part of MIS/endourology fellowships. However, MIS in urology has been established since the 1990s, ${ }^{13}$ and should be well integrated into current urology residency programs. In fact, the RCPSC objectives for training require that graduating urologists be able to independently perform an MIS nephrectomy. ${ }^{14}$ Despite the obvious importance of MIS nephrectomy, residency training in this procedure may
Table 3. Proportion of subspecialty trained fellows that obtained employment in an academic practice

\begin{tabular}{lc}
\hline & Academic practice \\
\hline Endourology/MIS & $36 \%(25 / 70)$ \\
Oncology & $54 \%(22 / 41)$ \\
Female/reconstructive surgery & $62 \%(13 / 21)$ \\
Pediatrics & $57 \%(12 / 21)$ \\
Infertility/andrology/erectile & $39 \%(7 / 18)$ \\
dysfunction & $77 \%(10 / 13)$ \\
Renal transplant & \\
\hline MIS: minimally invasive surgery. & \\
\hline
\end{tabular}

not be ideal, as there is considerable disagreement between staff urologists and residents regarding the degree of involvement during actual cases. ${ }^{15} \mathrm{~A}$ second contributing factor to the high number of MIS fellowships may be the available community employment opportunities; $64 \%$ of urologists who complete these fellowships are in community practice (a proportion that is higher than the other fellowship areas). Perhaps there is a real or perceived need for MIS fellowship training to enhance the skill set of existing community urology practice groups. A third possibility is that employment opportunities may be increasingly more difficult to come by, and therefore urologists are undertaking extra training while waiting for a job opportunity to arise.

There are multiple challenges to becoming a successful academic physician: the opportunity cost of extended training time, securing grant funding, time pressures, and understanding how to successfully conduct clinical research. Graduate degrees offer a structured, accredited program with research mentors. Canadian urologists appear to be incorporating graduate degrees into their fellowship and residency, with a significant increase in these graduate degrees over time. Most recently, $24 \%$ of graduating residents between 2008 and 2009 completed a graduate degree. However, an advance degree or research training does not always equate to practice in an academic centre. A third of the urologists in this study who obtained advanced degrees chose community practice; of the 114 residents who completed a fellowship with a significant research component, $37 \%$ went in community practice.

Table 4. Training and practice characteristics of urology graduates over the past 12 years based on academic or community practice* $^{*}$

\begin{tabular}{|c|c|c|c|c|}
\hline & $\begin{array}{l}\text { Entire cohort ( } n=258 \text { ) (including } \\
\text { those currently unemployed) }\end{array}$ & $\begin{array}{l}\text { Academic practice } \\
\qquad(\mathrm{n}=85)\end{array}$ & $\begin{array}{l}\text { Community practice } \\
(\mathrm{n}=166)\end{array}$ & Chi square test \\
\hline Fellowship training & $72 \%(185 / 258)$ & $100 \%(85 / 85)$ & $56 \%(93 / 166)$ & $p<0.0001^{*}$ \\
\hline Fellowships with research training & $62 \%(114 / 185)$ & $81 \%(68 / 84)$ & $46 \%(42 / 93)$ & $p<0.0001^{*}$ \\
\hline Graduate degree during residency/fellowship & $11 \%(28 / 258)$ & $24 \%(20 / 85)$ & $6 \%(10 / 166)$ & $p=0.0004^{*}$ \\
\hline Practicing within $100 \mathrm{~km}$ of training program & $49 \%(126 / 254)$ & $66 \%(56 / 85)$ & $40 \%(66 / 166)$ & $p<0.0001^{*}$ \\
\hline Left province of training program & $36 \%(91 / 253)$ & $31 \%(26 / 85)$ & $38 \%(62 / 166)$ & $p=0.2732$ \\
\hline Practicing in city with $<100,000$ population & $22 \%(56 / 254)$ & $1 \%(1 / 85)$ & $31 \%(51 / 166)$ & $p<0.0001^{*}$ \\
\hline Practicing in the United States & $16 \%(40 / 254)$ & $18 \%(15 / 85)$ & $13 \%(22 / 166)$ & $p=0.3527$ \\
\hline
\end{tabular}


Welk et al.

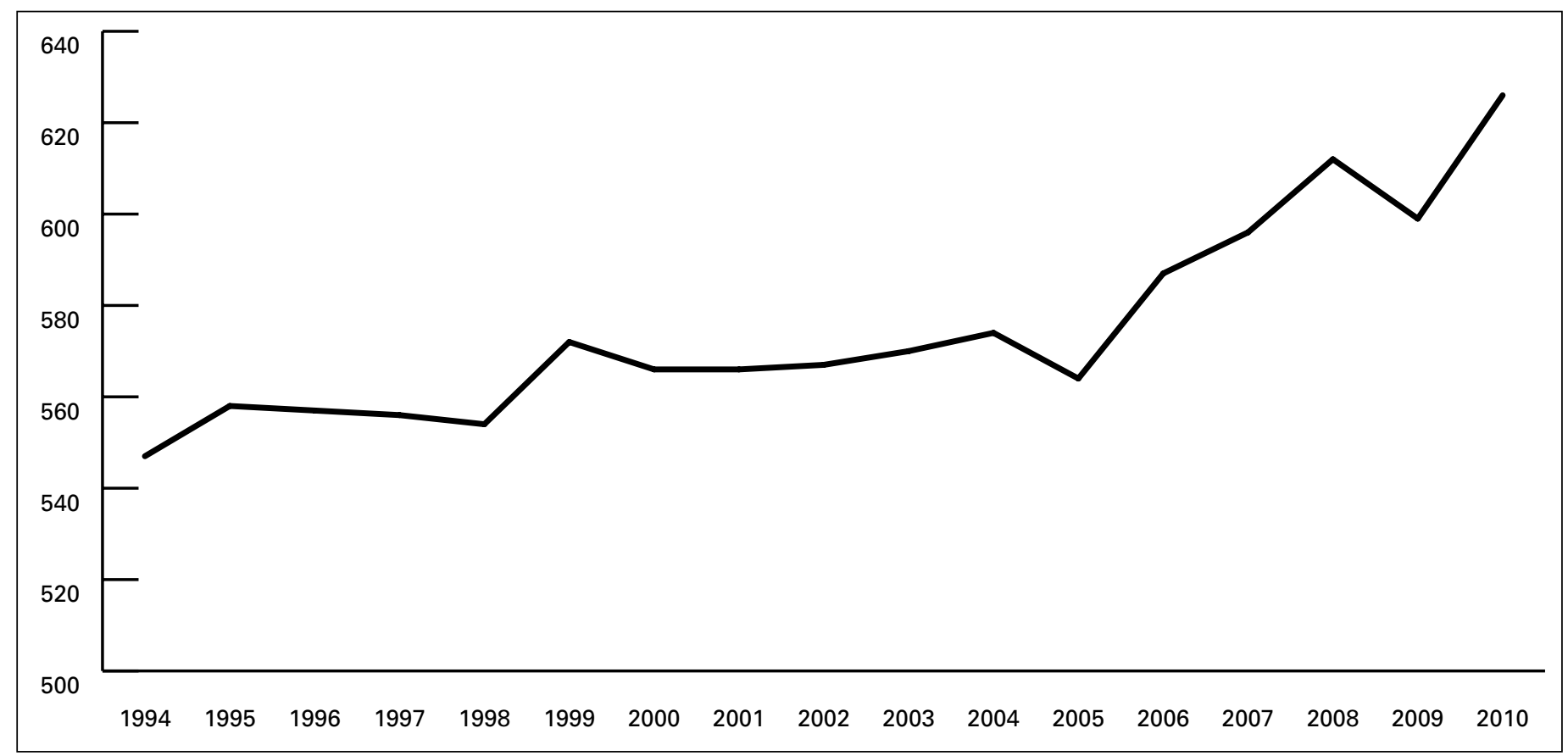

Fig. 3. Total number of practicing urologists in Canada.

Despite the perception among residents that there is a lack of employment opportunities, almost all Canadian urology residents that graduated between 1998 and 2009 are employed. The total number of practicing urologists in Canada has risen (Fig. 3); ${ }^{16}$ this suggests that the workforce is accommodating an increasing number of urologists. Other factors that would suggest there is a lack of jobs in Canada (i.e., residents moving out of province or moving to the United States to find employment) have not changed significantly over time. However, the "difficulty level" of obtaining these jobs was not directly measured in this study. These findings must also be tempered by the fact that the graduating urology cohort has not increased significantly over the study period. The 2011 newly admitted first year urology residents will not graduate until 2016, at which point the number of Canadian trained urology residents graduating each year will potentially be $50 \%$ greater than that seen during our study period.

The training centre of a urologist seems to have a significant influence on their eventual practice location: two-thirds of academic urologists return to their residency centre to practice, and half of all urologists practice within $100 \mathrm{~km}$ of their residency training city. This may be because of personal preference, the population distribution of Canada or a "regional" advantage for employment opportunities. This employment pattern is important, and should be considered when allocating additional training spots in the future.

A previous work force planning study for Ontario urologists was published in 1999 by Pace and colleagues. ${ }^{17}$ The authors estimated that there would be a shortage of urologists in Ontario by 2010 unless training spots were increased.
They calculated that 259 urologists would be required in 2010 (very similar to the 247 urologists that were found to be currently active in Ontario in $2010^{16}$ ). Continued efforts to increase practice numbers across the country by increasing hospital resources will be required to ensure timely access to urologic care for our aging population.

This study provides a picture of the fellowship training and employment choices made by Canadian urologists. These variables are likely to continue to change as urology and health care in Canada continue to evolve. Although this study suggests some reasons for the trends that have been observed, ultimately many factors not measured in this study likely play a significant role; these factors include the city where the urologist grew up, family influences and specific characteristics of individual job opportunities. The trends shown in this study are true only for the study period, and may change in the future.

\section{Conclusion}

Canadian urology graduates are more likely to undertake fellowship training and pursue graduate degrees than in past years. MIS/endourology fellowships have been increasingly popular over time, and this seems to be in preparation for community practice. Signs of difficulty finding employment, such moving to the United States or another province to practice, were not demonstrated. With increasing graduating cohorts expected, it is important that as a specialty we continue to monitor the employment and training patterns of urologists in Canada. 
Acknowledgement: Dr. Welk is supported by a Canadian Urologic Association Scholarship.

Competing interests: None declared.

This paper has been peer-reviewed.

\section{References}

1. Anderson MB, Kanter SL. Medical Education in the United States and Canada, 2010. Acad Med 2010;85:S2-S18. http://dx.doi.org/10.1097/ACM.0b013e3181f16f52

2. Beauchamp $G$. Surgical Education in the Canadian Socialized Health Care System. World I Surg 2007;31:1536-44. http://dx.doi.org/10.1007/s00268-007-9072-9

3. First Time Enrolment in Canadian Faculties of Medicine by Faculty of Medicine. http://www.afmc.ca/ publications-statistics-e.php. Accessed January 15, 2013.

4. Match Results for Canadian Medical Graduates by Year 1994-2010. http://www.carms.ca/ pdfs/2010R1_MatchResults/Match\%20Results\%20by\%20Year_en.pdf. Accessed January 15, 2013.

5. Comeau P. Crisis in orthopedic care: surgeon and resource shortage. CMAJ 2004;171:223. http:// dx.doi.org/10.1503/cmaj.1041073

6. Salazar JD, Ermis $P$, Laudito $A$, et al. Cardiothoracic surgery resident education: update on resident recruitment and job placement. Ann Thorac Surg 2006;82:1160-5. http://dx.doi.org/10.1016/i. athoracsur.2006.04.070
7. Vanderby SA, Carter MW, Latham T, et al. Modeling the Cardiac Surgery Workforce in Canada. Ann Thorac Surg 2010;90:467-73. http://dx.doi.org/10.1016/j.athoracsur.2010.04.056

8. Badley EM, Canizares M, Mahomed N, et al. Provision of Orthopaedic Workforce and Implications for Access to Orthopaedic Services in Ontario. J Bone Joint Surg Am 2011;93:863-70. http://dx.doi. org/10.2106/JBIS.I.01782

9. RCPSC: Examining why jobs are scarce for some specialists. http://rcpsc.medical.org/publications/ dialogue/vol 11-10/1/oversupply_e.php. Accessed January 15, 2013.

10. Touma NJ, Beiko D, Siemens DR. Career Outlooks and Choices of Graduating Canadian Urology Residents and Societal and Professional Implications [abstract]. Can Urol Assoc J 2011;5:S3-S114.

11. Bianco FJ, Cronin AM, Klein EA, et al. Fellowship Training as a Modifier of the Surgical Learning Curve. Acad Med 2010;85:863-8. http://dx.doi.org/10.1097/ACM.0b013e3181d73a45

12. Morrison KB, MacNeily AE. Core competencies in surgery: evaluating the goals of urology residency training in Canada. Can J Surg 2006;49:259-66.

13. Gill IS, Clayman RV, MCDougall EM. Advances in urological laparoscopy. J Urol 1995;154:1275-94. http://dx.doi.org/10.1016/S0022-5347(01)66839-3

14. RCPSC: Urology Training Objectives. http://rcpsc.medical.org/residency/certification/training/urology_e. pdf. Accessed January 15, 2013

15. Yap SA, DeLair SM, Tanaka ST, et al. Current perceptions of resident training in laparoscopic nephrectomy. Urology 2009;73:1067-71. http://dx.doi.org/10.1016/i.urology.2008.08.520

16. CMA physician demographics. http://www.cma.ca/multimedia/CMA/Content_Images/Inside_cma/ Statistics/historical/01SpecProv2010.pdf. Accessed January 15, 2013.

17. Pace KT, Provan JL, Jewett MA. The urology work force in Ontario for the 21st century: feast or famine? Can J Surg 1999;42:181-9.

Correspondence: Dr. Blayne Welk, B4-667 St Joseph's Health Care, 268 Grosvenor St., London ON N6A 4V2; fax: 519 646-6037; blayne.welk@sihc.london.on.ca 